\title{
Community-based flood risk management: lessons learned from the 2011 flood in central Thailand
}

\author{
N. Jukrkorn ${ }^{1}$, H. Sachdev ${ }^{2}$ \& O. Panya ${ }^{3}$ \\ ${ }^{1}$ Research and Development Institute, \\ Phranakorn Rajbhat University, Thailand \\ ${ }^{2}$ Faculty of Environment and Resource Study, \\ Mahidol University, Thailand \\ ${ }^{3}$ Greenpeace South East Asia
}

\begin{abstract}
Thailand mega floods in 2011 highlighted the need for an integrated approach to a flood risk management approach, combining local level community-based action and a national strategic policy in preparation and reduction of vulnerability of a country as a whole. This paper provides fact about a flood crisis in 2011 and a set of lessons learned of community-based flood risk management from affected communities scattered around the great flood areas in central Thailand. Data and insightful information were drawn from a field visit and a three-day participatory workshop attended by over 50 participants who had experience of the flood. Included in this were community people, representatives of local administration organizations and centralized agencies responsible for dealing with natural disaster and crises.

Lessons learned from the workshop are conceptualized into six knowledge platforms (KPs), highlighting the community best practices in response to the situation during and after the crisis. They include 1) structural measures; 2) nonstructural measures; 3) emergency responses; 4) how to cope with the community financial risk; 5) risk information and decision making; 6) dealing with floods crisis recovery planning.

Keywords: Thailand, community-based, flood response, flood risk management.
\end{abstract}




\section{Introduction}

The concept of flood risk management (FRM) has been widely embraced over the past decade. In many instances this conceptual acceptance has resulted in a change in decision making and practices highlighting risk management as potentially more complex, but more efficient and effective than a traditional engineering standard-based approach (Sayers et al. [3]).

The 2011 flooding crisis in Thailand undermined public confidence in the capacity of government to manage water resources, to guide responsible development, and to tackle recurrent and unforeseen emergencies. Many agreed that what was missing from the country's emergency flood response.

In retrospect, the problem was that the government pursued these measures with limited engagement of civil society, civil volunteers, the private sector, and the non-profit sector. As people suffered tremendously, the experience has propelled communities to take collective action in a manner consistent with traditional values of self-reliance. In these circumstances, citizens and civil society organizations began to help themselves by recruiting volunteers to gather new information on households in affected communities, and confirming the information and knowledge that they needed to secure proper assistance. Local communities and authorities, therefore, played a lead role in FRM, both in the short and long terms. It is also importance for local communities to review the process of FRM through identifying lessons from their knowledge and experiences that could be learned from past experiences and make improvements for future practices.

Data and information were drawn from field visit and a three-day participatory workshop. Over 50 participants who had had experience of the flood from both urban and rural community attended. As well, representatives of local administration organizations and centralize agencies responsible for dealing with natural disaster and crises. The workshop was manage based on the dialogue theory that can better motivate people to share experiences and knowledge (Bohm [2]). Every session of the workshop was taped recorded and subsequently transcribed into a text form of over 300 pages. Ethnographic interpretation was undertaken in order to draw upon some measures and future mechanisms that community could be integrated into future flood risk management.

\section{Facts about the 2011 flood crisis in Thailand: an overview}

Thailand had not foreseen an event of flood disaster. In the year 2011, the event was a high-impact and chaos phenomenon. Event with a low probability of occurrence, the damage was unprecedented and enormous. The floods hit 65 provinces, including 1052 districts, and 75 main highways were inaccessible. More than 1.5 million village people had suffered, more than 750 people were dead, and over 4 million people lives were affected. The country's loss of farmland is estimated at 5,110,327 acres of land cultivated, while 60,124 acres of fish ponds, animals were also affected by the floods. The losses of baht 32.41 
billion was estimated, due to the flooding impact over a long period of time. Major drivers causing the flood include the following.

\subsection{The highest record of rainfall and tropical storms and the flow capacity of rivers}

Since 1901, the rainfalls in 2011 were the historical record in Thailand (World Bank 2012). The heavy rainfalls in the latter period were the consequences of 5 tropical storms, (between the end of June to the beginning of October 2011 - see also Figure 1). Together, a study of World Bank (2012) states that one of the main causes of the flood crisis in 2011 was the low-flow capacity of the river (Lower North and Central Plains of Chao Phraya River and tributaries - see also Figure 2). Hence, water runoffs from major rivers had caused the overtopping of river dykes and breaching in any river tributaries.

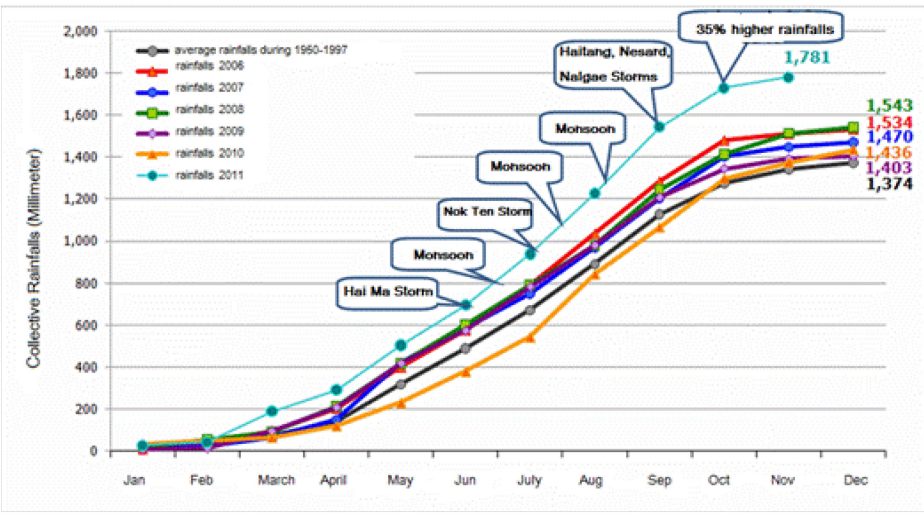

Figure 1: Average cumulative annual rainfalls - 1960-2011. (Source: Thailand Integrated Water Resources Management (www.thaiwater.net).)

\subsection{Country unplanned urbanization and land use change}

Rapid and unplanned urbanization and unsuitable land use in the flood plain areas is probably one of the most important factors worsening the floods in 2011. Ayutthaya province, where industrial and housing estates were located in the areas, were supposed to be the flood plains many infrastructural facilities had caused the blockage of the flood way. In Nonthaburi province, especially in Bangyai district, as semi urban-rural area located at western side of the lower Chao Praya river basin, flood plains and canals were also blocked by both the public and private infrastructure and urban sprawls. Many public canals simply disappeared because of illegal encroachments. Such changes in land use took away the ability to drain water from the northern part of Bangkok into the canals and drainage systems, and then to the drainage stations by the sea coast of the city. 


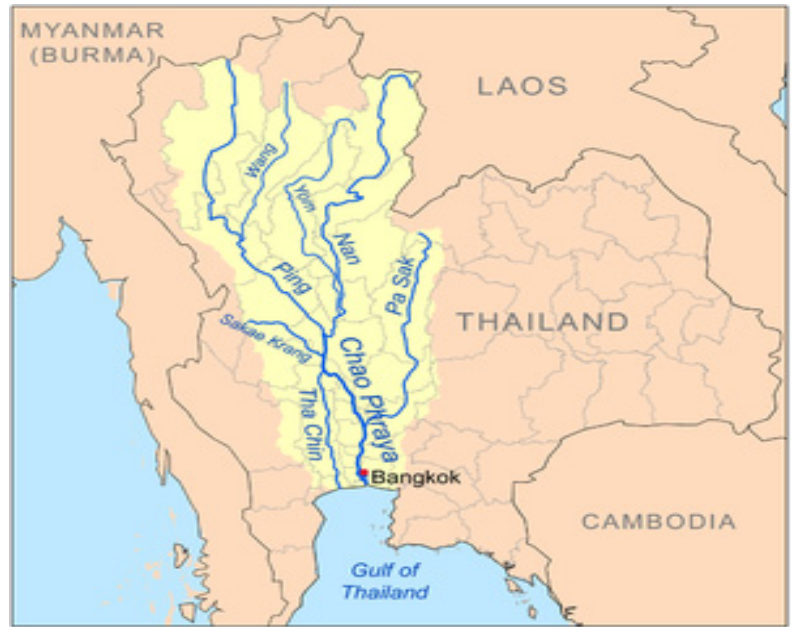

Figure 2: Chao Phraya River and tributaries. (Source: Google Maps.)

\subsection{Central government flood mismanagement and political intervention}

The floods crisis in 2011 was made worsened by man-made mistakes, particularly from the Central government mismanagement and political intervention includes:

\subsubsection{The weakness of the flood master plan, action plan, and policy responses from the central government}

Despite the severity of flood and the government quick responses, evidence showed there has been no concrete studies on the impact of the 2011 flood, by drafting a flood management master plan and allocating about 330,000 million baht (USD 11.3 billion) for the flood protection action plan as well as assistance and compensation for the flood victims. The action plan budget consisted of immediate flood compensation budget and budget for the flood action plans. Although the master plan consisted of both the plan on infrastructural investment, rehabilitation and maintenance, and the non-infrastructural plan, it does not give much attention to the latter, particularly in term of local agencies/communities involvement. No concrete policy and measures have been proposed, specially, inadequate attention to the complex long-term issues of fragmented water management and required institutional changes of integrated water management to cope extreme weather conditions, the appropriate combination of single command authority and decentralization.

\subsubsection{Weaknesses of existing operation and of major reservoirs}

Especially, the inflexibility on changes from higher authority when they needed to quickly change the schedule of gate opening in response to the emergency. Second, there was a lack of effective flood forecasting and early warning 
systems. Third, it had a lot to do with inadequate information on change in cropping patterns which affect the detailed gate operation schedule.

\subsubsection{Irrigation facilities maintenance failure}

During the flood crisis, at least 13 sluice gates were damaged, 3 of which collapsed and had caused big floods in some areas. The damages were not only caused by the big flood but also by the lack of proper maintenance of the flood protection infrastructure, which was the primary reason for structural failure and breaches of the flood protection embankment along the Chao Phraya River.

\subsubsection{Emergency mismanagement}

Slow responses to major sluice gate breakdowns, especially Bang Chom Sri sluice gate's collapse, clearly evident. There was too much water flowing into the entire Lopburi Province, and then and continued downwards to Ayuthaya district via Lopburi River. Not only because of the slow response, but the repair of Bang Chom Sri sluice gate was left to the resource-poor local government instead of professional central authorities.

\subsubsection{Political intervention on dam operation and irrigation management}

Along the Chao Phraya River, there were several barrages and dams that were used for regulating water for irrigation and flood management. Anyhow, there were, as newspaper reports claimed, some influential politicians might have influenced the decision in controlling the sluice gates and to delay the water discharge into one of the western provinces for some periods of time to allow the farmers in their constituency to harvest their rice crop.

\section{Key lessons learned from the flood in 2011}

Key lessons learned from the workshop delivered a set of lesson learned, sharing and exchanging among the participants. The discussion and synthesize cover what worked, what did not, and why in the response to the year 2011 flooding crisis. The event highlighted the key points in the field of community flood risk management and disaster response to flood detention areas, are as follows.

\subsection{Information and communication management is crucial in emergencies}

During the flood crisis, all participants pointed to two common information problems: i) the lack of real-time information on conditions and on coordination among parties (that is, on who is doing what); and ii) the loss of critical public records vital to reconstruction.

With regards to the first point, during the floods crisis the national government collected information from municipal governments, while additional information was crowd-sourced and channeled through social media and the Internet. Many post-disaster situations were made worse by the lack of communications strategies that make use of appropriate media to deliver critical messages. Good information enabled individuals and communities to not only stay safe but also contribute more effectively to relief and recovery. It also 
ensured that communities have a realistic set of expectations about relief and reconstruction. If communication was to help people stay safe and minimize the disruption to their lives, they must be able to trust the information and its sources. Together, communication regarding evacuation, temporary shelters, and emergency food distribution was mismanaged, creating confusion throughout the crisis phase of the flood.

\subsection{New crowd sourced information and the use of social media}

Social media, "community" radio stations were extensively used for searches and rescues. Social media included web-based applications that use the Internet to connect people (prominent examples are Twitter and Facebook), web sites and computer applications that enable users to collaborate and create contents, such as YouTube. Emergency "community" local radio stations also played a crucial role in the aftermath of the crisis. When the emergency communication systems in many cities broke down due to power failures and lack of emergency backup power, community radio stations were able to get useful information out to residents.

With the relatively high levels of mobile phone penetration in Thailand, social media could be very useful during disasters, to the extent that they are already used in normal times. They could also serve to link up with communities outside the flood-stricken areas to facilitate the acquisition and allocation of aid and assistance. In many developing countries, lack of physical accessibility to disaster-affected sites is a key issue. Mobile networks and social media can be used to collect and share localized information to improve accesses to rescue and relief efforts. Reliability and trustworthiness of information is an extremely important factor in the use of social media.

\subsection{Spreading a better understanding of risk planning and risk-assessment technologies need to be understood}

At the beginning, the government predicted a low probability of the floods risk occurring, and underestimated its size and the incoming monsoon risks. The official risk depicts areas that were small than the area actually affected by the floods.

In addition, accurate risk assessment and interactive communication systems which could connect local communities, government agencies, and experts, made people less vulnerable and more resilient. We have learned that under the enormous crisis and mismanagement of communication, community members should not be encouraged to stick to a single scenario. Community networking "flood information on land," (e.g., rise of water levels and flooding areas) would allow what was happening and what kind of preparation needed to the upstream and downstream flooding indication. At the same time, people in these communities all needed as frequent weather forecasts- "information from the sky," (weather monitor and forecast) as much as possible.

A better understanding of nature and limitations of risk planning among communities, local authorities and the population at large would have to improve 
their collective and individual decision making, especially in emergencies. Communication about the unfolding disaster could and should have been more interactive among local communities, governments, and experts. Distributing risks plans and issuing early warnings were not enough. In the event, the magnitude of the floods crisis was underestimated, which may have led people to delay their evacuation.

\subsection{Providing better evacuation centres, considering vulnerable groups and gender sensitivity}

At evacuation centers, the needs of women, kids, cross cultural people and the disabled were not fully met. The overwhelming majority of the leaders of community organizations were male. Relief goods delivered to the shelters were biased in favor of male evacuees. New measures are needed to assure privacy and security for all vulnerable groups and should be planned in advance. These measures call for empowering marginalized groups for long-term recovery and including a gender perspective in planning and managing shelters, which will require women to be more deeply involved in shelter management. Vulnerable groups must not only be protected but also engaged in decision making. Understanding and meeting the challenges of the elderly, children, and women, both during the emergency and in its aftermath, are priorities for effective post disaster response. Local cultural knowledge sound solutions that take account of special needs among segments of the population should be planned in advance in order to enhance resilience and facilitate recovery and reconstruction.

During the crisis, it was reported that shelters provided for did not give sufficient privacy for anyone, particularly for women, many of whom did not have private spaces where they could change their clothes or breast-feed their babies. At the peak of the relief effort, more than 2,000 people were housed in one evacuation centre, while some left their communities and stayed with relatives and friends who lives outside the flooded area. Most facilities, such as, schools and community centers, were publicly owned and were urgently set up as evacuation centers.

\subsection{Recovery planning on debris and waste management}

In the areas affected by the floods crisis, community representatives were organized on recovery planning committees from the earliest stages. The local governments outside the disaster-affected area helped affected municipalities plan their recovery. There was an urgent need to dispose tons of debris left behind by the floods crisis. The debris was an enormous obstacle impeding recovery plan. Among the many issues arose were that of the availability and selection of storage sites, methods of incineration, decisions about recycling, and waste treatment and disposals.

Because of the fact that maintaining existing sources of income and creating jobs were crucial during the recovery plan for communities, local and municipal governments were expected to professionally manage disaster related waste, 
select different treatment, different disposal methods in accordance with the composition of the debris.

\subsection{The importance of community participation in flood risk management}

During crisis, tradition of community participation in preparedness was a key factor in minimizing the number of lives damaged and lost. The role of the community goes far beyond evacuation. Prior measures to crisis should also be provided. This includes risk planning and warning systems, and ongoing education, all of which proved essential in the evacuation that followed the floods crisis. Local governments and communities in affected areas served as first responders, managers of evacuation centers, and planners of post disaster rehabilitation.

After the crisis, flood risk reduction activities should be well integrated into the daily lives of most communities, ensuring that awareness of floods risk management is never far from their mind. The national and local governments must recognize and support the involvement of the communities at risks through laws and regulations that define roles and commitments. This could be defined as a community-based approach in dealing with disasters. Decision making must come from this community-based organization involving local governments, organizations and people's participation. Although managing evacuation centers is a municipal responsibility, most municipalities in the disaster-affected areas suffered staff losses, seriously weakening their capacity to cope with the emergency as a result. At the beginning, most centers were supported by local school teachers, volunteers, and other civil society groups. As the evacuation period lengthened, evacuees themselves started taking initiatives to manage their communities. Experienced from the crisis, all participants were in agreement that social safety nets for vulnerable groups are needed in times of emergency and during recovery as a priority.

\subsection{Coordination mechanisms on the ground should be agreed upon before the fact}

During the crisis, coordination among various groups, such as governments (national and local), civil society organizations (CSOs), and private entities was often poor - or at least not optimal. Local governments, whose facilities in some cases were wiped out by the disaster, had little experience working with other large-scale organizations, As a result, they received insufficient supports from the central government in managing the new forms of cooperation.

Overall, the coordination system among local governmental organizations with the communities, central government agencies and relief organizations and donors was not up to the unprecedented task.

Effective coordination from stakeholders must develop. Although the national government managed to establish the rescue headquarters very quickly with inter prefectural emergencies and rescue units and technical forces were deployed in record time, the mechanisms for formal coordination among the various stakeholders (government agencies at all levels, CSOs, and private entities) were 
inadequate. One weakness of coordination observed on the ground during the flood demonstrated that coordination mechanisms should have been established with advanced agreements and clear definitions of responsibility.

\subsection{The need for a holistic approach to floods risk-management}

Single-sector development planning cannot address the complexity of problems posed by floods disasters. Faced with complex risks, flood-effected communities chose to build capacity by investing in preventive structural and nonstructural measures, by nurturing local culture and learning from past disasters, and by promoting cooperation among multiple stakeholders, between government agencies and ministries, between the private sector and the government, and between multiple levels of government, and from local to national levels. The essence of the approach is to design and maintain resilient infrastructure capable of absorbing damages caused by flood and natural disasters to an extent that they exceed all feasible and affordable measures. In the wake of the floods disaster, communities also recognized that additional efforts were required to plan and design measures capable of countering events of low probability but high impact.

\section{The guidelines for the future}

Echoing the key lessons learned from the workshop are conceptualized as Knowledge Platforms (KPs), highlighted the community best practices in the field of flood risk management. These KPs were grouped into six clusters, including the following.

\subsection{Structural measures}

Generally, check dams and dikes are both necessary and effective in preventing ordinary floods, which are relatively frequent, but they are of limited use against the extreme events that occur less frequently. As the case of Bang Chom Sri dam showed, construction standards and stability performance under worst-case scenarios should be further investigated. Structures should be able to withstand floods that exceed their designed flow, reducing the force of the water before they collapse and thereby mitigating damages.

The Central Government master plan generally put an emphasis on the structural flood management and little attention was given to the issues of nonstructural aspects of flood management. Efforts within flood risk management have to create solutions based on community ownership and consensus. By preparing and increasing community awareness and capacity of local governmental authorities to handle flood situations has been recognized as a focal point for flood risk management. After mega flood, government launch a mega project for flood protection, however it only focusing on construct dam and flood way. 


\subsection{Non-structural measures}

During the floods crisis, as occurred in many centers, a self-governing body emerged, with leaders and members of various committees selected by the evacuees themselves. Key actors were that of community-based organizations, who had saved many lives and needs of the victims. When the crisis management overwhelmed local agencies, local communities were forced to use their own knowledge and resources to survive on flood crisis chaos, save lives and assets. Fortunately, throughout the floods areas, communities had been engaged in floods preparedness. Therefore, knowledge of community-based flood risk management (CBFRM) is very useful for the FRM strategy in the future.

\subsection{Emergency response}

Partnerships needed to facilitate emergency operations: Coordination among governmental agencies, military forces, and other stakeholders in dealing with the emergency was an overwhelming challenge. The system for delivery of relief goods, evacuation centers and temporary housing should be supported from professional logistics specialists from local government in unaffected areas. The special needs of cross-cultural and vulnerable groups (including the elderly, children and the disabled) needed to be included in transition-shelter initiatives. In addition, the experience points to the importance of bringing in professional staff to care for the disabled and vulnerable. Considering the difficulties faced by local governments after the flood crisis, coordination mechanisms should be established in the central government, or under an umbrella organization.

\subsection{Coping with the financial risk}

During the 2011 flood crisis, full financial impact (including direct and indirect impacts) form flood disaster will not be known for some time. The government must play an important role in alleviating the disaster's impact on households and businesses through measures that ensure the stability of the financial system, timely approvals of supplementary budgets, and provisions for rapid disbursement disaster assistances, all of which helped citizens jumpstart their recovery processes. The financial resources for recovery and reconstruction are being funded by taxes to avoid leaving the cost to future generations. Flood insurance helps people get back on their feet. Governments can play an important role in fostering the growth of this kind of infrastructure, thereby enabling the private insurance industry to offer cost-effective and affordable insurance solutions.

\subsection{Risk information and decision making}

Risk information is needed to be understood. Uncertainties associated with floods risk probabilities should be assessed based on multiple options, taking 
into account every conceivable eventuality and utilizing all the tools science has to offer.

The sharing of information among governments, communities, and experts left much to be desired. While science-based early-warning systems are important during a disaster, it was best for the target population if it could combine with information on the ground through regular sharing of pre-disaster information at the local level. The sharing should be accompanied - over time and with the community's involvement - by disaster drills, community mapping exercises, and other measures. In recent years, remote-sensing data have been used around the world to rapidly map the damage resulting from natural disasters.

\subsection{Recovery planning}

In the areas affected by the floods crisis, communities were organized on recovery planning committees from the earliest stages. In general, authorities should be prepared for disasters by designating temporary storage sites, traffic routes for transporting waste; including hazardous and toxicity waste. The role of the private sector in debris management, as well as cooperation with organizations and government bodies outside the affected areas, should be explored. The possibility of recycling should be considered. Finally, rice and vegetable seeds as well as young fruit trees are of most needed by rural communities, as they could save a great deal of money on food and begin a new agricultural season without spending money on much of them.

\section{Conclusion}

Lesson learned from Thailand has pointed that, flood risk management implemented by communities and local government is crucial. Communities and local government have the opportunity to design solutions that are adaptable to the needs of their local communities and are consistent with local policies and priorities. The measures and possible future mechanisms in addressing community's flood risk-management. From the people's view, the integrated flood management mechanism does not have to rely entirely on the: "predictand-act' approach, which is conventionally used for the designed structural measures. The Thai experience showed that success of flood risk management lay in community involvement. Effective flood risk management requires close coordination among all affected areas, including all responsible municipalities as well as their agencies and departments, in order to support all-inclusive and country relevant solutions. Policy makers and urban/rural development experts both structural and non-structural aspects - should be well advised to listen to the communities and empower them to be the focal part of the solution.

\section{Acknowledgements}

The authors wish to thank, Asian Development Bank, for providing the budget for the workshop, community leader district and representatives from local government agencies in Thawung and BangYai Sub-district, as well as 
representatives from the Department of Disaster Prevention and Mitigation Minister for insightful information.

\section{References}

[1] Asian Development Bank, Community-based Flood Risk Management and Disaster Responses the report, 2013.

[2] Bohm, David, On Dialogue, London Routledge, 1996.

[3] Paul Sayers et al., Flood Risk Management A Strategic Approach, Paris UNESCO, 2013.

[4] World Bank, Thai Flood 2011. Rapid Assessment for Resilient Recovery and Reconstruction Planning, Bangkok, 2012. 